\title{
Butterfly Lesion on MRI: Cryptococcus Meningoencephalitis with Unusual Imaging in a Patient with AIDS
}

Mary Henary ${ }^{1}$, Jennifer Oster ${ }^{2}$, and Antonio Liu ${ }^{3}$

${ }^{1}$ Ross University School of Medicine

${ }^{2}$ Adventist Health White Memorial

${ }^{3}$ California Hospital Medical Center

November 6, 2020

\begin{abstract}
On magnetic resonance imaging (MRI), a butterfly lesion is most commonly described in Glioblastoma Multiforme (GBM), however we report an unusual case of Cryptococcus Meningoencephalitis with the butterfly lesion on MRI. This infection is generally diagnosed via lumbar puncture, however MRI may reveal perivascular space involvement, dilation and leptomeningeal enhancement.
\end{abstract}

\section{Hosted file}

Oster HIV Cryptococcus.pdf available at https://authorea.com/users/373613/articles/491254butterfly-lesion-on-mri-cryptococcus-meningoencephalitis-with-unusual-imaging-in-apatient-with-aids
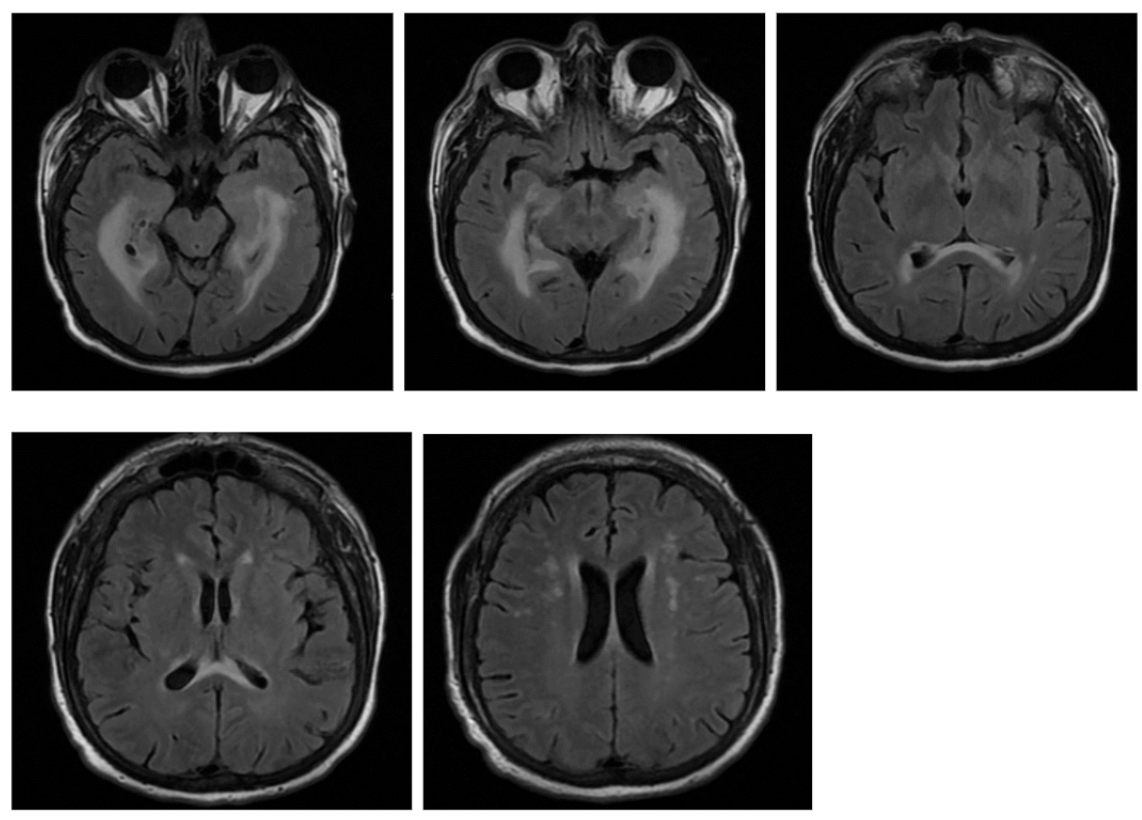